University of Nebraska - Lincoln

DigitalCommons@University of Nebraska - Lincoln

Biological Systems Engineering: Papers and

Publications

Biological Systems Engineering

$7-2020$

\title{
Classification of plant moisture conditions using canopy and leaf temperature responses to step changes of incident radiation
}

\author{
George Meyer \\ University of Nebraska - Lincoln, gmeyer1@unl.edu \\ Ellen T. Paparozzi \\ University of Nebraska - Lincoln, etp1@unl.edu \\ Erin Stevens \\ University of Nebraska - Lincoln
}

Follow this and additional works at: https://digitalcommons.unl.edu/biosysengfacpub

Part of the Bioresource and Agricultural Engineering Commons

Meyer, George; Paparozzi, Ellen T.; and Stevens, Erin, "Classification of plant moisture conditions using canopy and leaf temperature responses to step changes of incident radiation" (2020). Biological Systems Engineering: Papers and Publications. 768.

https://digitalcommons.unl.edu/biosysengfacpub/768

This Article is brought to you for free and open access by the Biological Systems Engineering at DigitalCommons@University of Nebraska - Lincoln. It has been accepted for inclusion in Biological Systems Engineering: Papers and Publications by an authorized administrator of DigitalCommons@University of Nebraska Lincoln. 


\title{
Classification of Plant Moisture Conditions Using Canopy and Leaf Temperature Responses to Step Changes of Incident Radiation
}

\author{
George E. Meyer, Professor Emeritus, Biological Systems Engineering \\ Ellen Paparozzi, Professor, Agronomy and Horticulture \\ Erin Stevens, Former Undergraduate Research Assistant, Biological Systems Engineering \\ University of Nebraska, Lincoln, NE 68583 \\ Written for presentation at the \\ 2020 ASABE Annual International Meeting \\ Sponsored by ASABE \\ Omaha, Nebraska \\ July 12-15, 2020
}

\begin{abstract}
.
Environmental and soil conditions affect plant productivity. Determining and understanding how plants respond to moisture stress may be considered in different ways, but often not easily done. This study focused on measuring canopy and individual leaf temperature response times of selected horticultural and agricultural crops, treated to very dry (moisture stress) and well-watered conditions, and subjected to an incident step radiation change at the top of the canopy, in a controlled environment at a constant air temperature. A light-emitting-diode (LED), grow light system, delivering approximately $400 \mu$ Einstein s-1 $\mathrm{m}^{-2}$ of photosynthetically-active-radiation (PAR) was turned on and off to produce light and dark radiation step functions for the tests. Canopy and leaf temperature time series were measured using both an infrared thermometer and a FLIR thermal imaging camera, over a 10-minute elapsed time, respectively. Temperatures of a selected single, unobstructed leaf at the top of the canopy were analyzed with visual and thermal imaging processing. Response data were modeled using mathematical transfer functions and model discovery methods. Both canopy and leaf temperature-time series for dry plants were found to be a first-order response. Well-watered plants were first order followed by second order response phase, possibly indicating stomatal activity. Thermal response times to a step increase of PAR (lights-on), were higher for well-watered plants than for water-deprived plants. (It took longer for the leaves of well-watered plants to heat up). The thermal response times, to a step decrease of PAR (lights off), were lower for wellwatered plants than for water-deprived plants. (It took less time for the leaves of well-watered plants to cool off). These results show that leaf thermal response may be used as an indicator of plant water status, and as a potential instrumentation approach.
\end{abstract}

Keywords. Plant canopy temperature, thermal imaging, leaf temperature, response time, moisture stress. 


\section{Background}

In order to feed the growing world population, it is crucial to increase crop yields and to minimize the resources used for agriculture. Understanding how plants respond to various environmental factors is crucial for increasing crop yields and quality, while regulating the amount of resources that are required to grow the crop. Plants respond to environmental stimuli, and the "speaking plant" approach suggests that optimal cultivation conditions should be determined by the physiological response of a plant (Hashimoto et al., 1985). For example, plant leaves are dynamic control systems that continually adjust to the aerial environment that surrounds them. Studying how a plant responds to different heat and moisture conditions could lead to more efficient irrigation systems, which would reduce water usage and increase crop quality, both in controlled environments (e.g. Greenhouses) and in the field (Bajwa et al., 2007).

One way that plants utilize a dynamic control system is through stomatal control for transpiration. Leaves cool themselves, using evaporative moisture exchange, through tiny pores on the bottom leaf surfaces called stomata. When stomata are open, water can exit the leaf, and therefore lower the temperature of the leaf as the water evaporates. However, when a plant is not receiving enough water, the hydraulic and biochemical signals tell the plant to conserve water by closing stomata. Such signals are sent from the roots, through the xylem to the shoots (Grant et al., 2007). However, stomatal closing results in the loss of temperature control through transpiration and causes the overall temperature of the plant to increase. This higher canopy temperature leads to more water use, which is inefficient (Al-Faraj et al., 1994).

A numerical index sometimes used in irrigation management is the Crop Water Stress Index (CWSI). The CWSI index assesses the crop moisture stress level at a given point in time, by using baselines developed from transpiring, wellwatered, and non-transpiring plants (Prenger 2003). The CWSI can be determined from the canopy temperature either empirically or theoretically (Idso et al., 1981, Jackson et al., 1981). However, there are limitations to using the CWSI as an irrigation scheduling tool since the empirical calculation requires assumptions, for example clear sky conditions and constant wind speed (Payero et al., 2005). This assumption is not always supportable in field conditions. It has been shown that both solar radiation levels and wind speed can affect the transpiration rates, not accounted for in the CWSI index, as a steady-state phenomenon. For this reason, the CWSI may not be the most accurate measurement of plant stress. An approach that assesses the dynamic nature of plant water relationships should be developed in order to provide the most accurate information about the plant at any given time.

Monitoring how stomatal conductance changes with time would be a very effective system for determining plant stress. However, measuring stomatal conductance is generally an invasive procedure, and only provides a single data point (Grant et al., 2007). Invasive methods for measuring stomatal resistances and leaf temperature have been used to determine plant stress. Such an invasive device called the steady state porometer has been available commercially for some time. This method relies on a hypothetical leaf energy balance and a psychrometrics model to compute a stomatal resistance value. However, it must be noted that canopy resistance is not a simple sum of the leaf resistances. Therefore, studying canopy responses has always had some degree of uncertainty associated with it (Pitacco et al., 1996). Therefore, leaf or canopy temperature has been suggested as an indirect measurement of stomatal conductance, and therefore an indicator of the stress level of the plant (Bajwa et al., 2007, Prenger et al., 2005, Grant et al., 2007, Prenger 2003,Boonen, et al., 2000, Al-Faraj et al., 1994, 2000, 2001). The question to be answered is how to use temperature effectively and noninvasively to accurately assess leaf or canopy heat and moisture stress.

Both infrared thermometry and thermal imaging provide non-invasive methods for collecting temperature data from a leaf or a canopy, without interfering with plant growth (Prenger et al., 2005, Grant et al., 2007). Infrared thermometers or thermocouples (IRT/c) depend on the Planck's radiation equation to detect the amount of radiation that a surface emits or absorbs, which is proportional to the fourth power of the absolute temperature of the surface (Cengel \& Boles, 2002). Infrared thermometers must be calibrated using a standard black body to ensure that they are giving correct readings. A serious limitation to using an infrared thermometer or an IRT/c is the field of view, or what surface does the sensor actually "see". Typically, infrared thermometers simply take a weighted average of the temperatures of the objects within its field of view (Woebbecke et al., 1994). In order to get a desired temperature reading, it is therefore crucial to eliminate unwanted objects from the field of view. However, this is especially difficult when measuring the canopy temperature where leaves are sparsely spaced, occluded, and/or where the infrared sensor will inevitably measure some of the soil temperatures or other background in the field of view.

Because of the limitations of the infrared thermometer, thermal imaging is being used in combination with infrared thermometers to try to eliminate some of the background noise in the temperature readings. Many studies have investigated the use of thermal imaging to gather canopy temperature data. because it will not interfere with normal plant growth and development functions (Grant et al., 2007). Thermal imaging has been used for a wide range of applications when studying plant response and plant stress. One study utilized thermal images to show how a water deficit develops in 
each individual leaf. They found that the edges of the leaves closed their stomates before the central sector. This means that the water status of a plant determined by a steady state porometer could be very different depending on the location on the leaf where a sample is taken from (Hashimoto et al., 1984). Another study used this information along with thermal imaging to create calibration curves to help estimate the stomatal conductance of different parts of the leaf (Jones et al., 1999). In yet another study, the combination of thermal imaging and visible light imaging was used to detect water stress under both drought and flood conditions for Sunagoke moss (Ondimu et al.,2008). Solar radiation is a very important factor that affects canopy temperature. A passing cloud in the field, can cause a step change in radiation received by the plant (Ondimu et al., 2008, Al-Faraj et al., 2000, Payero et al., 2005).

Studies by Al-Faraj's et al, (2000) considered the effect that step changes of irradiation had on well-watered, moderately stressed, or severely stressed plants, using both a mathematical leaf model and comparisons with actual measurements. They found that well-watered plants showed a second order, underdamped response, but as water stress increased, the damping response decreased, and ultimately disappeared in the severely stressed plants, which tended to show only a first order temperature response. This study also showed that as plant water stress increased, the transpiration rate decreased, and the severely stressed plants had a higher leaf temperature than the well-watered plants. Another study showed that plant physiological processes responded differently to a "lights-on" versus a "lights off" scenarios; suggesting that the "lights-on on" situation required three dynamic processes, while the "lights off" situation only relied on two processes (Boonen et al., 2002). Ultimately, canopy short wave lighting and incident solar radiation is again a factor that must be considered in canopy temperature measurements.

There is evidence that plants are dynamic control systems that are constantly responding to their environment (Boonen, 2005, Prenger et al., 2005). There are studies that show the effect that radiation has on the canopy temperature of a plant, but these studies have not considered the time it takes for a plant to begin to regulate its temperature, also known as the plant response time. The response time of plants has the potential to be used as an indicator of a stressed plant. Well-watered plants are assumed to transpire at maximum rates, thus cooling for stressed plant that is not transpiring at a maximum rate may not be as fast (Schymanski et al., 2013). Monitoring temperature changes over time is a way to observe the dynamic stomatal control of a leaf in action. While the leaf approaches the steady state temperature, small temperature deviations might be sinusoidal, which might indicate that the leaf is actively opening and closing the stomates to maintain its temperature. However, this temperature sine wave for a stressed plant may not be visible since the plant is not able to transpire to regulate its temperature. The steady state canopy temperature of a well-watered plant may be generally lower than that of a water-stressed plant due to the lack of transpiration (Al-Faraj, et al., 2000). This study focuses on measuring leaf and canopy temperatures in response to step changes in short wave radiation, as a potential indicator of water stress levels. If there is indeed such a correlation, a simple test that only takes a few minutes could be useful to show a plant's stress level. This could have a potential impact for irrigation scheduling, both in controlled environments such as greenhouses and perhaps in the field.

For this study, the leaf and canopy temperature response to a step change in incident short wave radiation was investigated for both well-watered and water-stressed plants. The specific objectives were:

1. To compare first-order response times for selected horticultural plant species.

2. To measure, model, and compare dynamic temperature responses for well-watered and water-stressed soybean canopies.

\section{Materials and Methods}

\section{Study Plants}

This study used four types of potted plants: common house plants, basil, and soybeans. Some of the plants were bought from a local garden center, and other plants were grown in the East Campus greenhouses at the University of Nebraska - Lincoln. Two to six plants were used. Soil mix was a common greenhouse mix which included composted bark. Plant species included: basil (Ocimum basilicum), golden pothos (Epipremnum aureum ), Maranta prayer plant (Maranta leuconeura), green oxalis (Oxalis triangularis) and soybean (Glycine max L. Merrill). Plants were grown in six-inch pots. All healthy plants were allowed dry down and then re-watered in sunlit conditions for two days. Plants were then tested under both dried down and well-watered conditions. 


\section{Step Incident Radiation Tests}

Incident, step radiation tests were conducted within a CONVIRON E15 reach-in environmental chamber (Controlled Environments Ltd, Winnipeg, Canada), located in Chase Hall, University of Nebraska, Lincoln. Air temperature was set to a constant $22^{\circ} \mathrm{C}$. Lighting was provided by a light- emitting- diode (LED) bank (S720 Advance Spectrum MAX LED Grow Light Panel (GrowAce.com, division of Niche Webstores, Inc, CA), designed for growing plants. The LED full spectrum lights consisted of 240 diodes and had a footprint of illumination of $0.9 \times 1.7 \mathrm{~m}$, with a high intensity discharge (HID) equivalent of $960 \mathrm{~W}$. Figure 1 shows the key elements of the test system.

Individual plants were each subjected to both an "LED lights-on" and followed by a "LED lights-off" test. "LED lights-on" were adjusted at the top of each canopy to provide $400 \pm 20 \mu$ Einsteins $/ \mathrm{m}^{2}$ ·s. "LED lights-off" registered around $-3 \pm 0.3 \mu$ Einsteins $/ \mathrm{m}^{2} \cdot \mathrm{s}$ (essentially dark). (Most total radiation sensors will not work unless especially calibrated for LED lights). The lights-on test was conducted first, and the lights-off test was conducted immediately after the conclusion of the lights-on test. The lights-off test began with a plant that was already at a high leaf temperature, so that cooling could be observed. After the data acquisition phase of the test, response times were calculated. The data was saved to be revisited and analyzed later (Stevens, et al, 2018). Later studies used real time processing described below. All response tests during this study were run for at least a period of 10 minutes. Samples of air and leaf temperatures, humidity, soil moisture, and radiation (PAR) along with thermal images of the canopy were acquired for 15 second intervals during each test period.

\section{Mathematical Dynamic Response Model Discovery}

Plant leaves are natural thermal control systems through sensible and latent heat exchanges and stomatal control. Mathematical modeling is an excellent way to describe the nature and the parameters of a real-world, dynamic plant thermal energy balances. Therefore, the Laplace transform is an important analytical tool for evaluating control systems and can be used to determine whether a system is a first order or second order heating or cooling control process. This transfer function for dynamic models is based on the complex variable: $s=\sigma+j \cdot \omega$. As an example, considering one zero (numerator) and two poles (denominator), the coefficients for a second order transfer function, are given as:

$$
\text { Transfer function }=\frac{\mathrm{a}_{1} \cdot \mathrm{s}+\mathrm{a}_{2}}{\mathrm{~s}^{2}+\mathrm{b}_{1} \cdot \mathrm{s}+\mathrm{b}_{2}}
$$

Using the first law of thermodynamics, consider a sensible heating or cooling energy balance statement for a leaf, simply given as:

$$
\dot{\mathrm{Q}}_{\mathrm{net}}=\dot{\mathrm{Q}}_{\mathrm{in}}-\dot{\mathrm{Q}}_{\mathrm{out}}=\Delta \dot{\mathrm{H}}_{\text {Leaf }}
$$

where:

$$
\dot{\mathrm{Q}}_{\text {net }}=\text { net leaf heat absorption rate from solar or artificial lighting sources and heat losses, } \mathrm{kJ} \mathrm{s}^{-1} \text {. }
$$

$$
\Delta \dot{\mathrm{H}}_{\text {Leaf }}=\mathrm{m} \cdot \mathrm{c}_{\mathrm{p}} \cdot \frac{\mathrm{dT}_{\text {Leaf }}}{\mathrm{dt}} \text { is the intrinsic change in leaf internal energy plus a small amount of }
$$

boundary work expansion or contraction, or leaf enthalpy, $\mathrm{kJ} \mathrm{s}^{-1}$.

The leaf's dynamic temperature change $\frac{\mathrm{dT}_{\text {Leaf }}}{\mathrm{dt}}$ might be approximated as a first order differential equation, given as:

$$
\frac{\mathrm{dT}_{\text {Leaf }}}{\mathrm{dt}}+\frac{\mathrm{T}_{\text {Leaf }}}{\tau}=\frac{\mathrm{T}_{\mathrm{m}}}{\tau}
$$

where:

$\mathrm{T}_{\text {leaf }} \quad$ is the current leaf temperature at time $\mathrm{t},{ }^{\circ} \mathrm{C}$,

$\mathrm{T}_{\mathrm{m}} \quad$ is the maximum steady-state leaf temperature, close to air temperature $\mathrm{T}_{\text {air }},{ }^{\circ} \mathrm{C}$,

A is the exposed surface area of the leaf to the LED radiation, $\mathrm{m}^{2}$,

$\mathrm{h}$ is a leaf to air, latent-sensible convective heat transfer coefficient, $\mathrm{kJ} / \mathrm{sec} \cdot \mathrm{m}^{2} \cdot{ }^{\circ} \mathrm{C}$,

$\mathrm{m} \quad$ is an approximate mass of the leaf, $\mathrm{kg}$,

$\mathrm{c}_{\mathrm{p}} \quad$ is the specific heat of the leaf, $\mathrm{kJ} / \mathrm{kg}{ }^{\circ} \mathrm{C}$,

$t \quad$ is the elapsed time, sec. 
Thus, four of the above factors can be combined into a single time constant $\tau$, where:

$\tau=\frac{\mathrm{m} \cdot \mathrm{c}_{\mathrm{p}}}{\mathrm{h} \cdot \mathrm{A}}$ is the response time coefficient for rise or decline in leaf temperature, sec. $\tau$ is essentially a relationship for the thermal mass (m) of a leaf or canopy, along with a sensible and latent heat exchange coefficient $h$ between the plant and its surroundings.

If a leaf indeed responds only as a first-order system, an approximate first-order transfer function can be given as:

First order transfer function $=\frac{\mathrm{a}_{1}}{\mathrm{~s}+\mathrm{b}_{1}}$

$$
\text { where: } \begin{aligned}
\mathrm{b}_{1} & =\frac{1}{\tau} \text { and, } \mathrm{a}_{1}=\frac{\mathrm{k}}{\tau} \\
\mathrm{k} & =\text { steady state gain. }
\end{aligned}
$$

Equation 4 can be simplified to Equation 5, given as:

$$
\text { First Order Transfer Function or Model }=\frac{\mathrm{k}}{\tau \cdot \mathrm{s}+1}
$$

\section{First Order Rise Time Coefficients Using a Graphical Method}

If the thermal response of a leaf to a step change in incident radiation is a first-order process, it is very easy to graphically determine the response time $\tau$ from time series data. The gain $\mathrm{k}$ will be positive. The $63 \%$ method of determining the rise time constant can be used to determine the response time of the leaf for the light-on tests. Integrating Equation 3 , a general form of a step rise response process can be written as:

$$
\mathrm{T}(\mathrm{t})=\left(\mathrm{T}_{\text {leaf }}-\mathrm{T}_{\mathrm{m}}\right) \cdot\left(1-\mathrm{e}^{-\mathrm{t} / \tau}\right)+\mathrm{T}_{\mathrm{m}}
$$

where $\mathrm{T}(\mathrm{t})=$ temperature at which the response time is determined; $\mathrm{T}_{\text {leaf }}$ is the steady state leaf temperature; $\mathrm{T}_{\mathrm{m}} \geq \mathrm{T}_{\text {air }}=$ surrounding air temperature (assumed constant); $\mathrm{t}=$ elapsed time $(\mathrm{s})$; and $\tau=$ time constant. When the time constant $(\tau)$ is equal to the elapsed time $(\mathrm{t})$, the exponent becomes -1 , and the overall equation becomes:

$$
\mathrm{T}(\mathrm{t})=(0.632) \cdot\left(\mathrm{T}_{\text {leaf }}-\mathrm{T}_{\mathrm{m}}\right)+\mathrm{T}_{\mathrm{m}}
$$

Based on Equation 7, the time constant for a rise response is equivalent to the time it takes for the output response to reach $63.2 \%$ of the steady state value. The light on tests conducted in this study follow this general equation form, therefore the response time could be calculated graphically using the $63 \%$ method.

\section{First Order Decay Time Coefficient}

The $37 \%$ method for determining the decay time constant can be used to determine the cooling response time of the leaf with the light-off tests. The general form of a step decay response process is written as

$$
\mathrm{T}(\mathrm{t})=\left(\mathrm{T}_{\text {leaf }}-\mathrm{T}_{\mathrm{m}}\right) \cdot\left(1-\mathrm{e}^{\mathrm{t} / \tau}\right)+\mathrm{T}_{\mathrm{m}}
$$

Where: $\mathrm{T}(\mathrm{t})=$ temperature over which the response time is determined; $\mathrm{T}_{\text {leaf }}=$ initial leaf temperature; $\mathrm{T}_{\text {air }}=$ surrounding air temperature (assumed constant); $\mathrm{t}=$ elapsed time $(\mathrm{s})$; and $\tau=$ time constant. becomes:

When the time constant $(\tau)$ is equal to the elapsed time $(t)$, the exponent becomes -1 , and the overall equation

$$
\mathrm{T}(\mathrm{t})=(0.368) \cdot\left(\mathrm{T}_{\text {leaf }}-\mathrm{T}_{\mathrm{m}}\right)+\mathrm{T}_{\mathrm{m}}
$$

The response time of the leaf is an important factor for many processes, particularly photosynthesis, respiration, and transpiration of a green plant. To study leaf thermal response, a computer program was developed to determine both rise time and decay time constants for different air temperatures, soil water condition, and short-wave radiation. More details about how the program was developed and used to determine these constants can be found in the LabVIEW Programs section under Materials and Methods. The rise time constant method described below assumes that the air temperature is constant. Leaf temperature will rise to a steady state value when subjected to a sudden increase in short wave radiation. Similarly, the fall or decay time constant method described below assumes that the function decays to a constant air temperature. 


\section{Sensors and Instrumentation}

The relative humidity of the chamber was measured using a LabJack EI1050 temperature and relative humidity probe (LabJack Corporation, Lakewood, CO, USA) which can measure relative humidity to an accuracy of $+/-3.5 \%$ (LabJack, 2018). Photosynthetically active radiation (PAR) was measured with a Li-190SA quantum sensor (LI-COR Inc., Lincoln, NE, USA). The background wall temperatures in the chamber were measured by an Omega OS36 IRT/c sensor (Omega Engineering Inc., Stamford, CT, USA), which acts like a type K thermocouple (Omega Engineering, Inc., 1994). The canopy temperature was measured with a Mikron MI-N3000 infrared sensor (Mikron Infrared, Oakland, NJ, USA) placed just above the plant. The MI-N3000 sensor has a field of view of 5:1. Meaning that for a distance of $50 \mathrm{~cm}$, the spot size of the sensor would be $10 \mathrm{~cm}$. The MI-N3000 also has a response time of $300 \mathrm{~ms}$ and can measure temperatures from $0^{\circ} \mathrm{C}$ to $500^{\circ} \mathrm{C}$ with an accuracy of $1.5 \%$ of that range (Mikron Infrared). These sensors are shown in Figure 1.

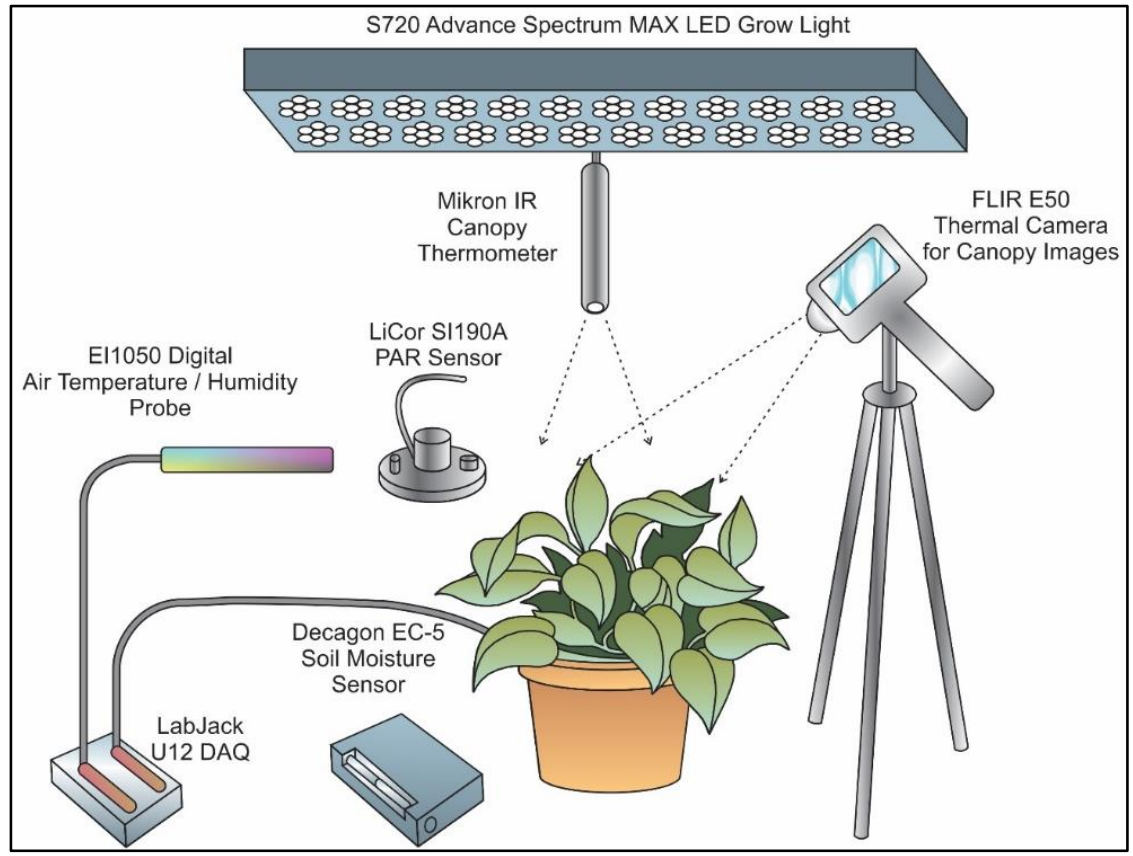

Figure 1. Schematic showing the key elements of the growth chamber experimental setup.

A pair of data acquisition devices and sensors were used concurrently in this study. One channel of a two-channel USB ProXR controller (National Control Devices, LLC, Osceola, MO, USA) was used to control the LED bank using LabVIEW. A Measurement Computing 8 Channel Thermocouple and Voltage USB DAQ Module (Measurement Computing Corporation, Norton, MA, USA) was used for the irradiance sensors and the type K thermocouple sensors. One thermocouple (Omega OS36 IRT/c) was used for determining the background wall temperature of the chamber, and the other thermocouple was connected to a black body plate as a reference point temperature. A LabJack U12 (LabJack, corp., Denver, $\mathrm{CO}$ ) multifunction device was used for acquiring air temperature and relative humidity data using the LabJack 1050, Sensiron ${ }^{\mathrm{TM}}$ sensor, as well as a Decagon EC-5 soil moisture sensor data. The volumetric water content (VWC) of the soil media was measured as a voltage using a Decagon EC-5 capacitance sensor (Decagon Devices Inc., Pullman, WA, USA). This sensor can measure water content with an accuracy of $+/-3 \%$ for a variety of soil types (Decagon Devices, Inc., 2010). The EC-5 sensors were used to find voltages for both saturated and dry soils, as relative reference for moisture conditions.

\section{Software to Control Data Acquisition and Processing}

A specialized LabVIEW 2015 (National Instruments, Austin, TX, USA) program or Virtual Instruments (VI) was programmed for the study. The flow diagram for the program is shown in Figure 2. The program was developed as a LabVIEW state machine to allow the user the manual selection of various operations such as: to acquire data and thermal images, compute first-order response times, analyze thermal images, and save the results to a file. The state machine is a programming algorithm that uses a combination of event, case, and loop structures (all within a single, while loop for continuous operation, until the user stops the program). Each state is dependent either on a previous state, or on a user selected function. For the data and thermal image acquisition state machine, the user was able to select the length of time desired to acquire data, and the number of samples that are taken each minute. After selecting these parameters, data was acquired with the LED lights "on" or "off" process, as a step function. 


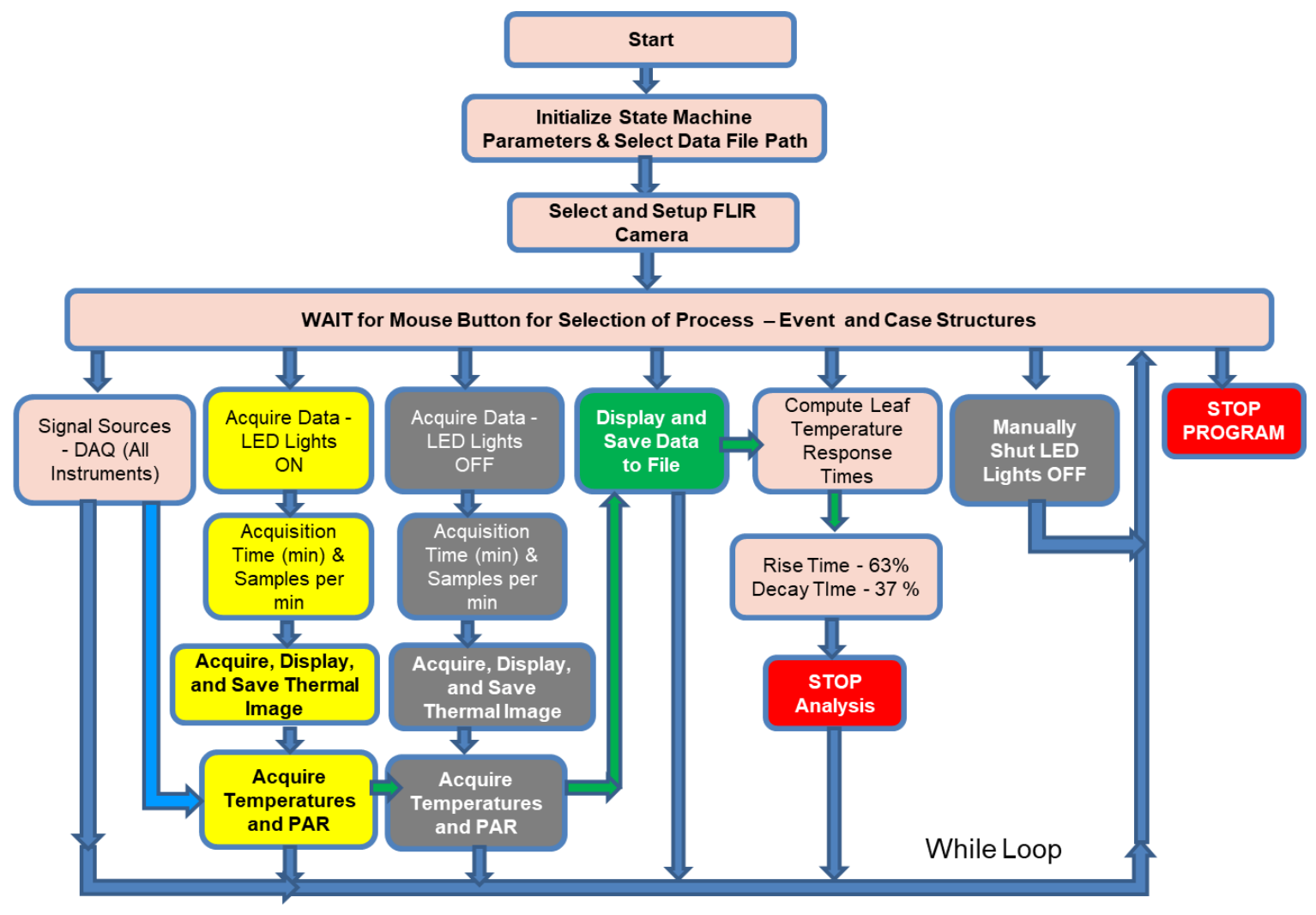

Figure 2. Flow chart showing the Operations of the LabVIEW Data Acquisition State Machine program

This LabVIEW program can collect and temporarily store data from all of the sensors using shift registers, as well as capturing and saving images from the FLIR E50 thermal imaging camera. Sample sequences of FLIR thermal images are shown in Figure 3. These thumbnails in false rainbow color indicate that the darker leaves were generally different from their surroundings. These images were captured separately using the FLIR camera, as a webcam, and are what would be seen directly on the FLIR camera monitor. FLIR provided all necessary functions for the E50 camera system with their ThermoVision LabVIEW Toolkit ${ }^{\mathrm{TM}}$. FLIR images are especially encapsulated with temperature data and the calibration information. All data was then saved to a user selected Windows folder. Thermal images ( $320 \times 240$ pixels) were acquired using a FLIR E-50 handheld thermal camera (FLIR Systems, Wilsonville, OR, USA) placed on a tripod in the growth chamber and focused on the plant leaves. FLIR Thermal images of the canopy were acquired simultaneously with the other data and analyzed after each different test was run. The FLIR E50 has a thermal sensitivity of less than $0.05{ }^{\circ} \mathrm{C}$ and an accuracy of $\pm 2{ }^{\circ} \mathrm{C}$. An emissivity value of 0.95 was set on the camera. Maximum and minimum target temperature ranges were recorded within each image. All data from each test was saved together to provide a complete set of Mikron and FLIR image temperatures.

After the leaf temperature data was collected for the desired length of time, the user was also able to immediately conduct a first-order leaf response time analysis, shown by Figure 4. A manual first order leaf response time, sub (VI) utilized three different user cursors to determine the response time constants from the temperature -time graph. A near virtual cursor was placed on the initial data point in the graph, and the far virtual cursor was lined up to the steady state temperature value. Next, a target virtual cursor was moved along the graph until it reached either $63 \%$ for a rising graph or $37 \%$ for a decaying graph. Once all cursors were placed properly, the response time was immediately calculated and displayed. The user had the option to save the data collected for each sample data point over time from all the sensors in the chamber into a convenient displayed table which could be easily transferred into Microsoft Excel for further analysis, if desired. 


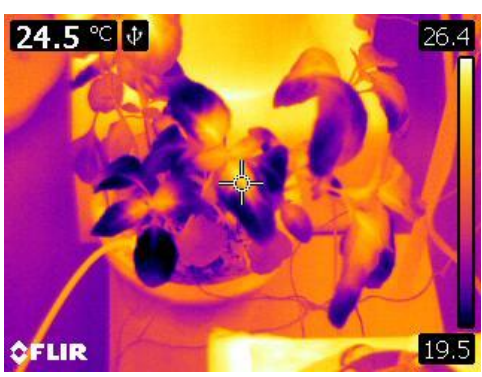

(1)

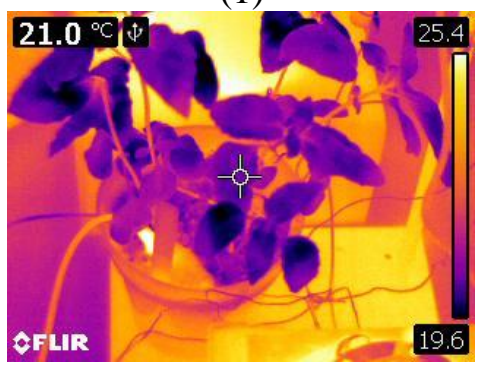

(4)

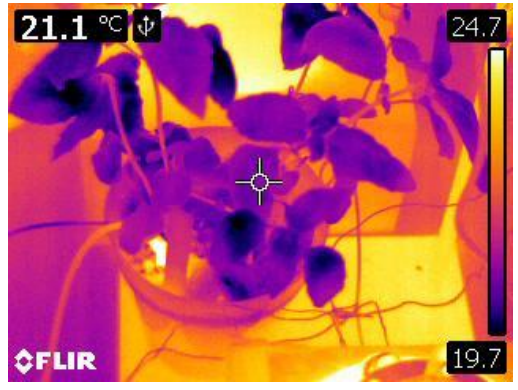

(7)

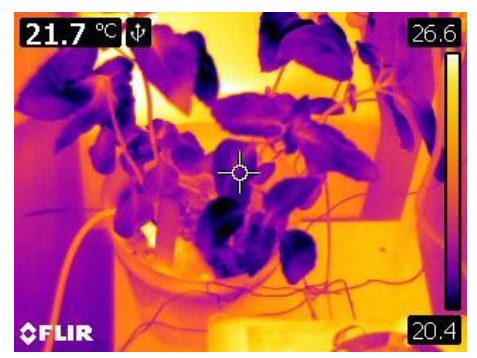

(2)

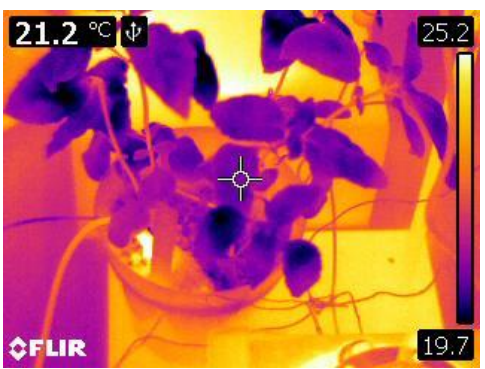

(5)

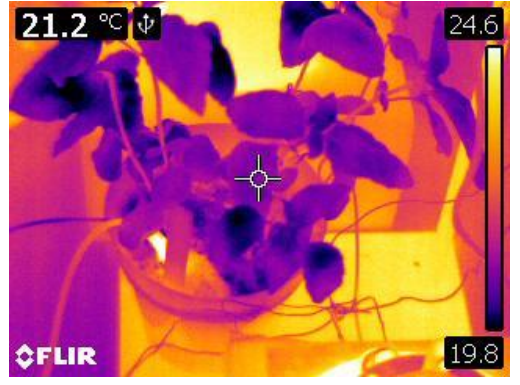

(8)

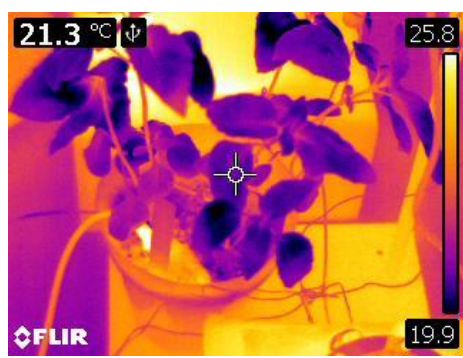

(3)

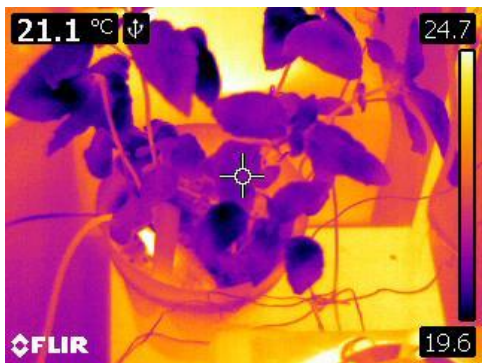

(6)

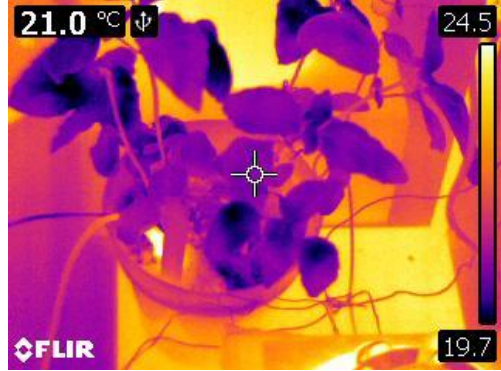

(9)

Figure 3. Sample sequence of nine FLIR thermal leaf images for Basil with LED Lights Off (cooling).

Using Equation 9, the time constant for a decay response is equivalent to the time it takes for the output response to reach $36.8 \%$ of the initial value. The gain $\mathrm{k}$ will be negative. The light off tests conducted in this study follow this general equation form, therefore this response time could be calculated using the $37 \%$ method. During this study, the initial value in the light-on test, and the steady state value in the light-off tests was assumed to be the maximum leaf or the maximum Mikron temperatures. A screenshot of the LabVIEW manual graphical response time analysis program is shown in Figure 4. Using the process of active cursors, three points are selected on the chart with the mouse: the initial temperature, the estimated steady-state temperature, and the $63 \%$ or $37 \%$ response time temperature. The appropriate response time is calculated from either equation 7 or 9 .

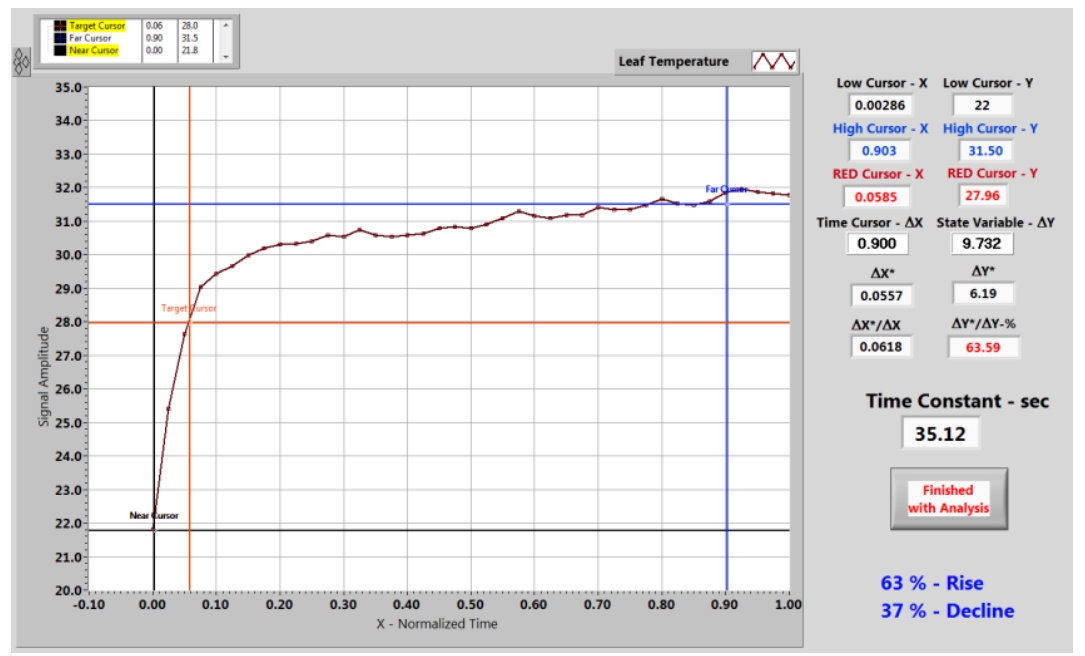

Figure 4. LabVIEW Front Panel for manual graphical response time analysis. 


\section{Thermal Leaf Image Transfer Functions}

Heat loss or gain by the plant canopy can be affected by both leaf mass and water content changes, and movement as a result of air turbulence, and possible leaf heliotropism (soybeans). The previous work of Al-Faraj, et al (2000) suggested that canopy temperature responses of fescue could be either first-order or second-order processes, depending on soil water conditions. A LabVIEW subprogram designated as the "Thermal Leaf Image Analyzer" was developed for this study. The Thermal Image Analyzer allowed the user to import a previously saved FLIR thermal image. The flow chart for the automated leaf analysis subprogram is shown in Figure 5. Each FLIR (.img) image has the minimum and maximum temperatures embedded within each image file for conversion of the raw pixels to temperatures. To perform image analysis, one whole leaf was selected at the top of the canopy, outlined as a template with the mouse, and then analyzed for leaf temperature. The leaves selected generally faced the LED bank. The analysis resulted in the experimental mean and standard deviation of leaf temperature during each time step of the test. A stimulus data set was also created based on the maximum temperature rise or gain and used as a step function.

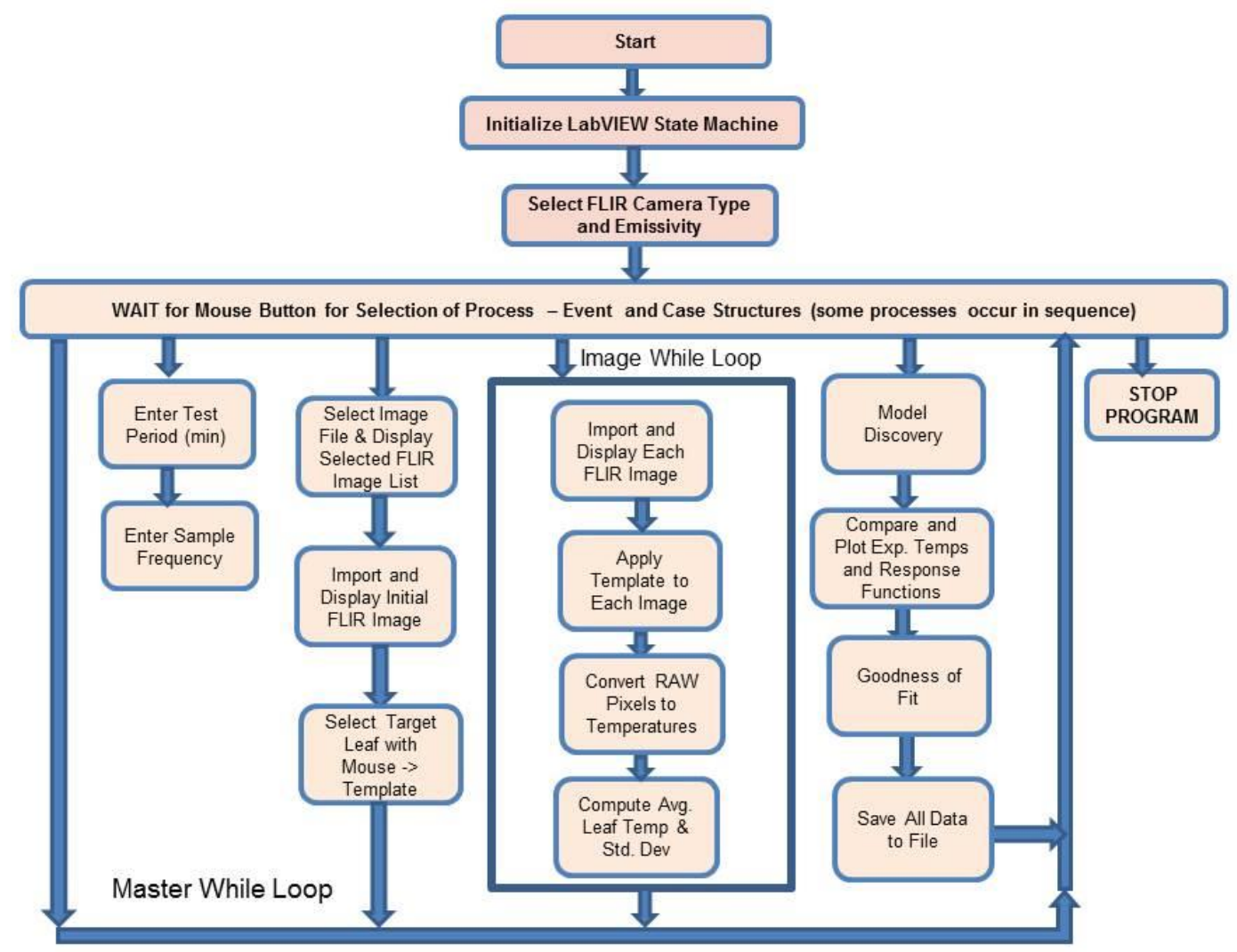

Figure 5. Flow chart showing the operations of an Automated Leaf Thermal Image Analysis program.

Two LabVIEW model discovery functions were used: SI Estimate Transfer Function Model VI and CD Construct Transfer Function Model VI (Continuous-time transfer or model builder function) and step (step response for the model simulator) function, which allowed simulated data to be computed and compared with the experimental response data. The first function allows the user to designate the order of the transfer function to be found, in this case first order. The second function automatically selects the transfer function order, which was second order.

Each LabVIEW function has two important input parameters: number of poles and number of zeros. Poles and zeros of a transfer function are the frequencies for which values of the denominator and numerator of transfer function becomes zero, respectively. The values of the poles and the zeros of a system determine whether the control system is stable, and how well the system performs (Nise, 1992). Each function was used to estimate the parameters of a continuous or discrete transfer function model for each unknown system of leaf temperatures.

The mouse template shown in Figure 6 followed each numbered FLIR image and the originally selected leaf for each response test. The user outlined a selected leaf on the initial FLIR thermal image with the mouse, resulting in a specific whole leaf edge contour (in this case, the shape of a specific leaf to be followed thermally). 


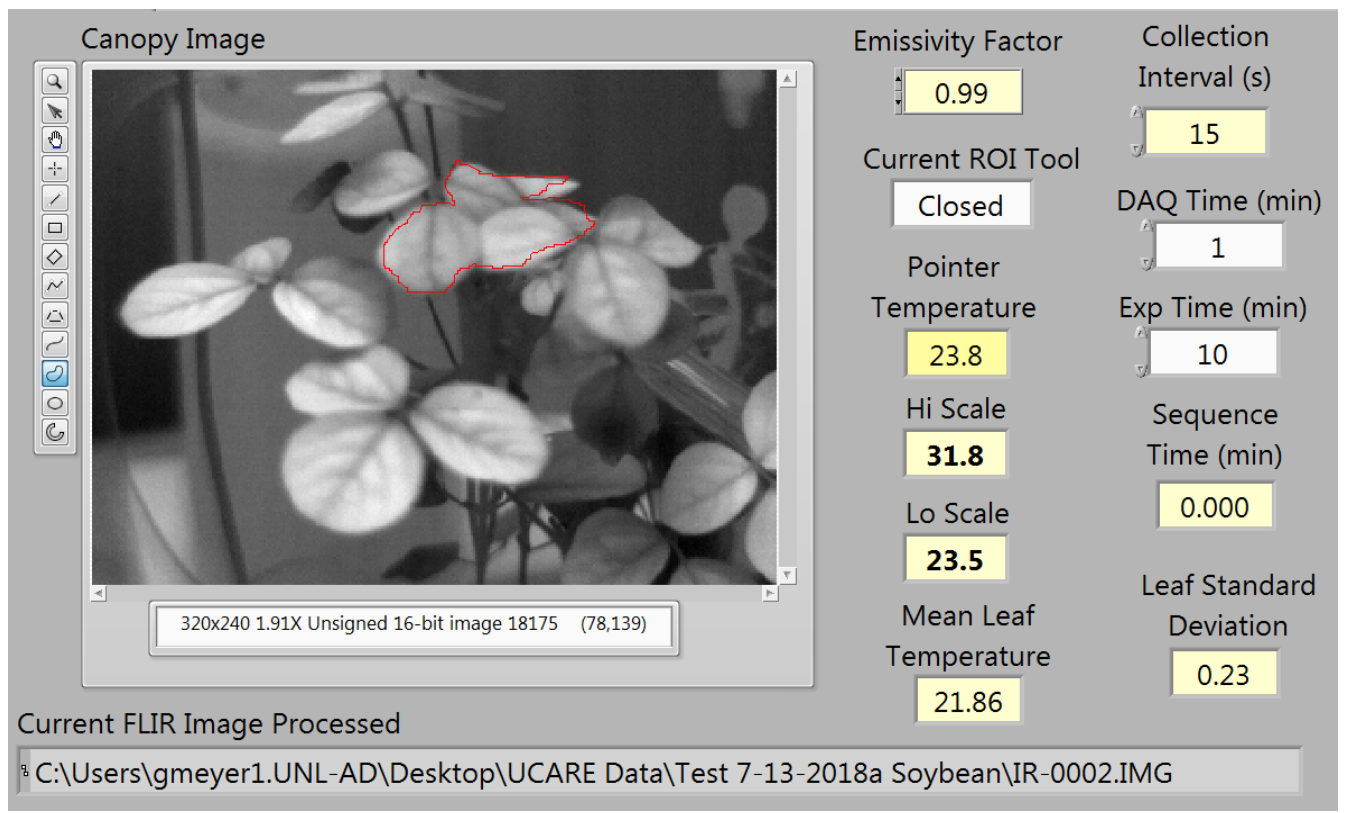

Figure 6. Extracting selected leaf temperatures from FLIR thermal images, using a mouse generated graphical template (in red).

When the contour was closed, the program automatically began the temperature analysis for the sequence of all thermal images, and then temporarily held the data. The program did pause after each image, to allow adjustment of the template, in case the leaf moved. The program then calculated the average leaf temperature and standard deviation of each selected leaf in the sequence. When the time test period was completed, all leaf temperatures and deviations were saved. Transfer functions obtained were compared graphically and statistically with the experimental temperature time series data.

\section{Results and Discussion}

\section{First Order Graphical Time Constants Using Simple Graphical Methods}

The first order response part of any step heating process would be related to the amount of leaf mass and moisture. While Al-Faraj, et al (2000) presented the possibility that a plant could have either first-order or second order leaf temperature control responses; a graphical method response time results would focus only on the first-order response (Equation 5). Household plants may not respond to water stress as much as field crops, due to tolerance of lower light levels. What happens after the initial heating or cooling of a plant leaf can be a complicated process. A summary of response times determined using the first order graphical method for plants are shown in Table 1. Graphical results were reported by Stevens, et.al. (2018).

\section{Green Basil}

Two green basil plants were used in the Stevens study, one was water-stressed, and the other was well-watered. The water-stressed plant was tested twice in a lights-on test, and twice in a lights-off test. The well-watered plant was also tested twice in a lights-on test, and twice in a lights-off test. For each of these tests, the Thermal Image Analyzer program was used to find the average temperature of a fully exposed, single leaf at the top of the canopy. The canopy response times were calculated for all tests using the LabVIEW state machine program, the single leaf response times were calculated by hand, and these times are shown in Table 1. The response times for both analysis methods support the hypothesis since the wellwatered basil plant had longer response times in both the lights-on and lights-off tests. A high degree of variability was observed in the well-watered times compared to the water-stressed times. The response curves generally showed that the infrared thermometer consistently measured a higher temperature than the average temperature for the single leaf determined by the thermal image analysis program. This may be due to other objects in the field of view of the thermometer. 
Table 1. Summary of Average First Order Response Times $\tau$ for Well-Watered and Water-Stressed Plants using the using the Graphical Method

\begin{tabular}{|c|c|c|c|c|c|c|c|c|}
\hline \multicolumn{9}{|c|}{ Green Basil $\tau$ Response Times } \\
\hline \multirow{3}{*}{$\begin{array}{l}\text { Radiation Step } \\
\text { Moisture Class }\end{array}$} & \multicolumn{4}{|c|}{ Canopy Analysis ${ }^{1}$} & \multicolumn{4}{|c|}{ Single Leaf Analysis ${ }^{2}$} \\
\hline & \multicolumn{2}{|c|}{ LED Lights-on } & \multicolumn{2}{|c|}{ LED Lights-off } & \multicolumn{2}{|c|}{ LED Lights-on } & \multicolumn{2}{|c|}{ LED Lights- off } \\
\hline & $\tau(\mathrm{s})$ & $\begin{array}{l}\text { Std Dev } \\
\text { (s) }\end{array}$ & $\tau(\mathrm{s})$ & $\begin{array}{l}\text { Std Dev } \\
\text { (s) }\end{array}$ & $\tau(\mathrm{s})$ & $\begin{array}{l}\text { Std Dev } \\
\text { (s) }\end{array}$ & $\tau(\mathrm{s})$ & $\begin{array}{l}\text { Std Dev } \\
\text { (s) }\end{array}$ \\
\hline Water-Stressed & 41.05 & \pm 2.57 & 22.90 & \pm 2.57 & 39.38 & \pm 2.65 & 24.53 & \pm 2.44 \\
\hline Well-Watered & 54.96 & \pm 5.13 & 31.97 & \pm 10.27 & 50.88 & \pm 12.20 & 35.53 & \pm 10.37 \\
\hline \multicolumn{9}{|c|}{ Pothos $\tau$ Response Times } \\
\hline Water-Stressed & 51.73 & \pm 9.70 & 30.16 & \pm 3.13 & 57.32 & \pm 7.29 & 76.97 & \pm 10.98 \\
\hline Well-Watered & 73.31 & \pm 8.94 & 36.00 & \pm 4.63 & 63.91 & \pm 12.75 & 61.25 & \pm 5.40 \\
\hline \multicolumn{9}{|c|}{ Prayer Plant $\tau$ Response Times } \\
\hline Water-Stressed & 42.86 & \pm 6.29 & 26.32 & \pm 2.79 & 35.00 & \pm 3.27 & 72.50 & \pm 1.64 \\
\hline Well-Watered & 94.90 & \pm 20.96 & 33.18 & \pm 5.54 & 52.14 & \pm 15.20 & 56.07 & \pm 28.39 \\
\hline \multicolumn{9}{|c|}{ Green Oxalis $\tau$ Response Times } \\
\hline Water-Stressed & 99.75 & \pm 7.38 & 52.54 & \pm 5.54 & 36.78 & \pm 4.06 & 74.29 & \pm 28.39 \\
\hline Well-Watered & 107.40 & \pm 4.85 & 52.94 & \pm 16.43 & 49.64 & \pm 6.28 & 43.45 & \pm 5.70 \\
\hline
\end{tabular}

1 Average response time $\tau$ determined from canopy temperatures using the Micron Infrared thermometer.

2 Average response time $\tau$ determined from selection and sequence of temperatures for a single thermal leaf image located at the top of the plant canopy.

Pothos

Two pothos plants were used in the Stevens study. Both plants started out water-stressed, and each plant was tested three times in a lights-on test, and three times in a lights-off test. After these tests were finished, both plants were watered, and these well-watered plants were tested three times in a lights-on test and three times in a light-off test. For each of these tests, the Thermal Image Analyzer program was used to find the average temperature of a fully exposed single leaf at the top of the canopy. Both the canopy temperature data and the single leaf temperature data were averaged for both plants The canopy response times were calculated for all tests using the LabVIEW state machine program, the single leaf response times were calculated by hand, and these times are shown in Table 1 . The variability data is not consistent when comparing the well-watered tests and the water-stressed tests. The canopy response times support the hypothesis since the well-watered plants had longer response times in both the light-on and light-off tests. However, the single leaf response times had mixed results, with the well-watered plant having a longer response time in the light-on test, but a shorter response time in the light-off test.

\section{Prayer Plant}

Of the two prayer plants that were used in this study, one was water-stressed, and the other was well-watered. The water-stressed plant was tested three times in a light-on test, and three times in a light-off test. The well-watered plant 
was also tested three times in a light-on test, and three times in a light-off test. For each of these tests, the Thermal Image Analyzer program was used to find the average temperature of a fully exposed single leaf at the top of the canopy. Both the canopy temperature data and the single leaf temperature data were graphed with respect to time. The canopy response times were calculated for all tests using the LabVIEW state machine program, the single leaf response times were calculated by hand, and these times are shown in Table 1. There is a high degree of variability in the well-watered response times compared to the water-stressed response times. The response times support the hypothesis since the wellwatered prayer plant had longer response times in both the light-on and light-off tests.

\section{Green Oxalis}

Two green oxalis plants were used in this study. One plant was water-stressed, while the other plant was wellwatered. The water-stressed plant was tested three times in a light-on test, and three times in a light-off test. The wellwatered plant was also tested three times in a light-on test, and three times in a light-off test. For each of these tests, the Thermal Image Analyzer program was used to find the average temperature of a fully exposed single leaf at the top of the canopy. Both the canopy temperature data and the single leaf temperature data were graphed with respect to time. The canopy response times were calculated for all tests using the LabVIEW state machine program, the single leaf response times were calculated by hand, and these times are shown in Table 1 . The variability data is inconsistent between the wellwatered and water-stressed tests. The canopy response times support the hypothesis since the well-watered oxalis plant had longer response times in both the light-on test but values for the lights-off tests. However, the single leaf response times do not support the hypothesis since the well-watered plant had shorter response times in both the light-on and lightoff tests. This difference may be due to the location of the leaf selected for analysis.

\section{Model Discovery Process}

Table 2 shows calculated transfer function coefficients (numerator a's, and denominator b's) using the LabVIEW model discovery approach. These are based on the LabVIEW SI Estimate Transfer Function Model VI and CD Construct Transfer Function Model VI (Continuous-time transfer or model builder functions).Comparisons of first and second order simulated responses to experimental leaf temperature data for a well-watered and dry soil soybean plants, are shown in Figures 7 and 8, respectively. Figure 7 shows that a soybean plant that has not been watered for a week, responds as a first order step response. The second order response follows the first order response very closely and the mean square errors of fit are almost identical. However, after an extended watering treatment, Figure 8 shows that some leaf cooling was derived after the initial temperature increase. The subsequent cooling could have been a result of stomatal activity and/or leaf movement.

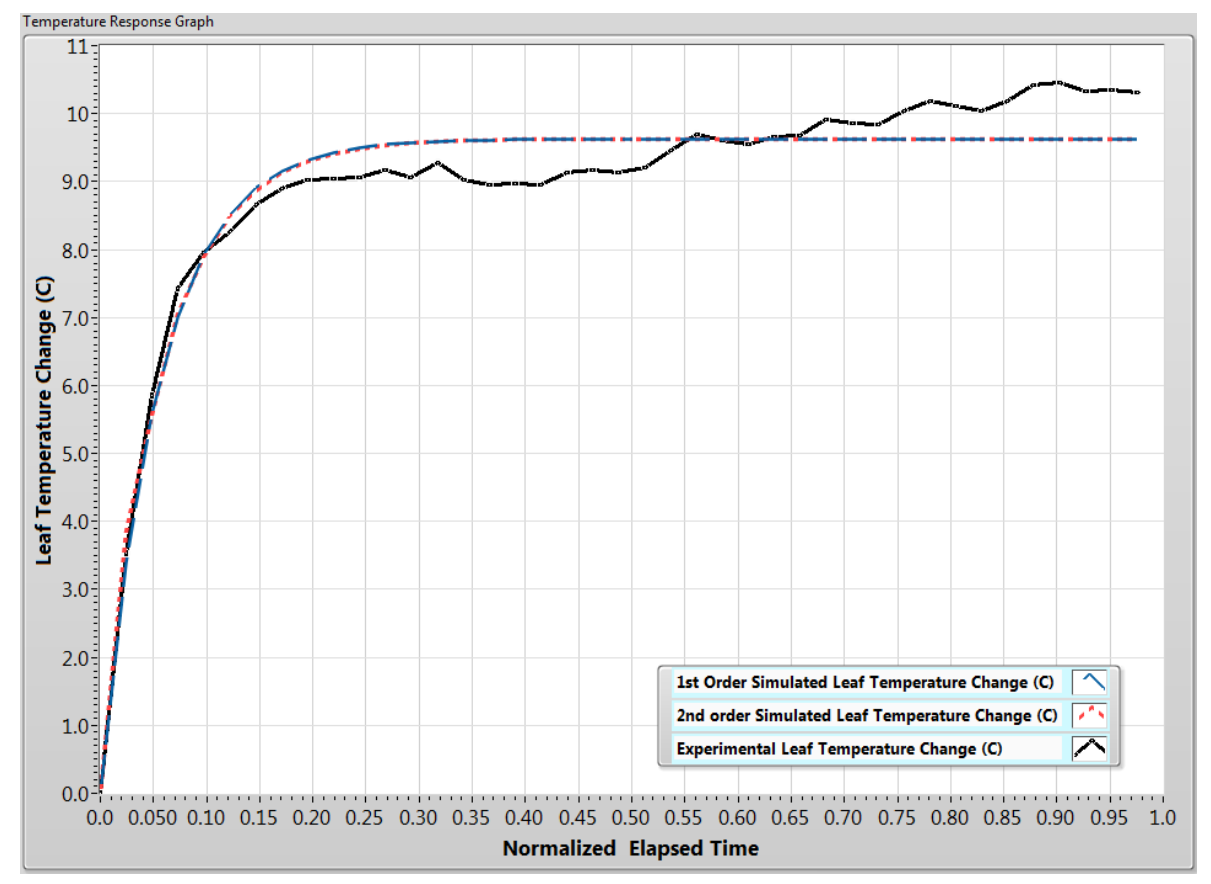

Figure 7. Comparison of First and Second order transfer function simulations and experimental leaf temperature response data (LED Lights-on) for a dry soybean plant. 


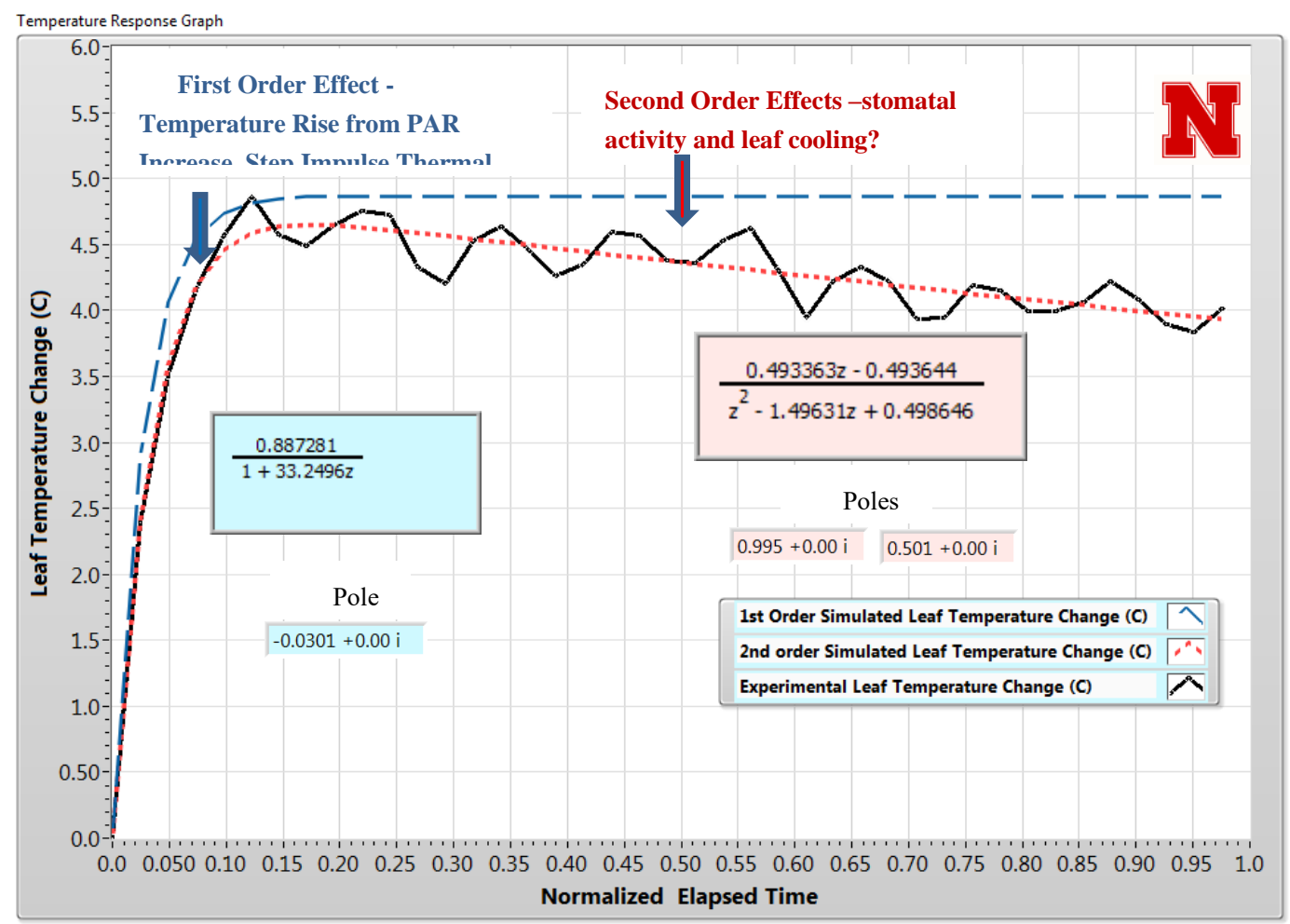

Figure 8. Comparison of First and Second order transfer function simulations and experimental leaf temperature response data (LED Lights-on on) for a well-watered soybean plant.

Noting that if coefficients $\mathrm{a}_{2}$ and $\mathrm{b}_{2}$ of a second-order response function are very small, such a transfer response equation may be approximated to a first order transfer function, by assuming that these small coefficients are close to zero. Table 2 provides a summary of first and second order simulations and mean square error goodness of fits to experimental leaf temperature data for various plants. The lower the mean square error, the better is the fit. The first-order temperature gain $\mathrm{k}$ represents the rise or decline in temperature of a leaf or the entire canopy as heat is gained or loss by leaf or canopy, respectively. The time constant $\tau$ represents the amount of time required to reach a steady temperature. This gives some credibility to manually determined time constants using the graphical method, as previously described in the Materials and Methods section.

\section{Conclusions}

The first project objective was to determine if canopy and/or leaf temperature response times could be used as an indicator of water status in a plant. After conducting tests on several different plant species, it was concluded that wellwatered plants may have a longer response time to a step change in radiation than water-stressed plants, therefore leaf response time might be a useful indicator of plant water stress. Measuring leaf thermal response times can be done quickly and easily with the graphical method, but must be done under controlled or managed conditions, whether in an environmental chamber of the field. Thermal response times may be an appropriate representation of the moisture stress level of a plant, rather than a simple incidental or static measurements of the canopy temperature, because of the dynamic process of a plant responding to its changing environment. The development of an instrument to measure response time could have a major impact on the design of irrigation control systems for greenhouses as well as in the field. Although this project only used a few plant species, tests could be easily replicated for other species in future studies. In future studies, response times could be measured in a greenhouse setting, as opposed to a growth chamber to see if response time indeed indicates the water stress level of the plant. There were differences between the use of an infrared thermometer and thermal leaf images. Future studies could also investigate using response time in a field environment. 
Table 2. Laplace Transfer Function Coefficients obtained from sequences of measure leaf temperatures, for Lights-on Step Tests Using Model Discovery ${ }^{[a]}$.

\begin{tabular}{|c|c|c|c|c|c|c|c|c|c|c|}
\hline \multirow[t]{2}{*}{$\underline{\text { Plant }}$} & \multirow{2}{*}{$\begin{array}{c}\underline{\text { Plant }} \\
\frac{\text { Moisture }}{\underline{\text { Status }}}\end{array}$} & \multirow{2}{*}{$\begin{array}{c}\underline{\text { Transfer }} \\
\underline{\text { Function }} \\
\underline{\text { Order }}\end{array}$} & \multicolumn{2}{|c|}{$\begin{array}{l}\text { Numerator } \\
\text { Coefficients }\end{array}$} & \multicolumn{3}{|c|}{$\underline{\text { Denominator Coefficients }}$} & \multirow{2}{*}{$\begin{array}{c}\frac{\text { Goodness of }}{\underline{\text { Fit }}} \\
\frac{\text { Mean Square }}{\underline{\text { Error }}}\end{array}$} & \multirow{2}{*}{$\begin{array}{l}\underline{\mathrm{Tau}} \\
\underline{\mathrm{sec}}\end{array}$} & \multirow{2}{*}{$\begin{array}{l}\underline{\text { Gain }} \\
{ }^{0} \mathrm{C}\end{array}$} \\
\hline & & & $\underline{\mathrm{a}_{0}}$ & $\underline{\mathrm{a} 1}$ & $\underline{b_{0}}$ & $\underline{b_{1}}$ & $\underline{\mathrm{b}_{2}}$ & & & \\
\hline \multirow[t]{2}{*}{$\underline{\text { Rhoeo }}$} & $\underline{\text { Unknown }}$ & $\underline{1^{\mathrm{st}}}$ & $\underline{1.001}$ & $=$ & $\underline{1.00}$ & $\underline{305.5}$ & $=$ & $\underline{0.00668}$ & $\underline{339.6}$ & $\underline{6.808}$ \\
\hline & $\underline{\text { Unknown }}$ & $\underline{2 n d}$ & $\underline{-0.0155}$ & $\underline{0.0163}$ & $\underline{1.00}$ & $\underline{-2.00}$ & $\underline{1.00}$ & $\underline{5.89}$ & $=$ & $=$ \\
\hline \multirow{4}{*}{ Soybean } & $\underline{\text { Dry }}$ & $\underline{1^{\mathrm{st}}}$ & $\underline{0.9207}$ & $=$ & $\underline{1.00}$ & $\underline{69.35}$ & $=$ & $\underline{0.198}$ & $\underline{69.35}$ & $\underline{10.45}$ \\
\hline & $\underline{\text { Dry }}$ & $\underline{2 n d}$ & $\underline{0.0736}$ & $\underline{0.368}$ & $\underline{-0.272}$ & $\underline{-0.248}$ & $\underline{1.00}$ & $\underline{0.196}$ & $=$ & $=$ \\
\hline & $\underline{\text { Wet }}$ & $\underline{1}^{\mathrm{st}}$ & $\underline{0.924}$ & $=$ & $\underline{1.00}$ & $\underline{45.69}$ & $=$ & $\underline{0.80}$ & 45.7 & $\underline{6.8}$ \\
\hline & $\underline{\text { Wet }}$ & $\underline{2 n d}$ & $\underline{-0.112}$ & $\underline{0.110}$ & $\underline{0.932}$ & $\underline{-1.93}$ & $\underline{1.00}$ & $\underline{0.84}$ & $=$ & $=$ \\
\hline
\end{tabular}

[a] Based on the LabVIEW SI Estimate Transfer Function Model VI and CD Construct Transfer Function Model VI (Continuous-time transfer or model builder functions).

The second project objective was to compare response times of different species. The response times of each species was similar within each species, but which had a large variance among species. The leaf anatomy including cuticle and leaf thickness and size of the leaves may have an impact on the variance between species. The basil and prayer plant have leaves of similar thickness, and they responded similarly in terms of the variance of the well-watered versus waterstressed tests. The pothos plant, which has larger, variegated leaves does not follow the same variance pattern as the basil and prayer plants. The oxalis plant, which has much smaller, clover-shaped leaves, also had a different variance pattern. In general, the response times of the well-watered plants were longer than the response times of water-stressed plants within the same species, but the same correlation was not necessarily true when comparing all species. It is important to get baseline data for a species of interest for response times to be used as an indicator of water status since response times are not consistent across all species.

\section{Acknowledgements}

Special thanks are given to the University of Nebraska Undergraduate Creative Activities and Research Experiences (UCARE) Program, funded in part by gifts from the Pepsi Quasi Endowment and Union Bank \& Trust for supporting this research for two years. Special thanks are also given to the USDA/ CSREES Multistate project NE-1335 "Commercial greenhouse production: Components and System". Special thanks are also given to Sheila Smith (BSEN Artist, retired), who prepared Figure 1 from photographs of the experiment. The mention of specific trade names is for reference only and not to the exclusion of other commercial productions.

\section{References}

Al-Faraj, A., Meyer, G. E., \& Fitzgerald, J. B. (1994). Simulated water use and canopy resistance of New Guinea Impatiens (Impatiens X hb) in single pots using infrared heating. Transactions of the ASAE, 37(6), 1973-1980.

Al-Faraj, A., Meyer, G. E., \& Horst, G. L. (2001). A crop water stress index for tall fescue (Festuca arundinacea Schreb.) irrigation decision-making - a traditional method. Computers and Electronics in Agriculture, 31, 107-124.

Al-Faraj, A., Meyer, G. E., Schade, G. R., \& Horst, G. L. (2000). Dynamic analysis of moisture stress in tall fescue (Festuca arundinacea) using canopy temperature, irradiation, and vapor deficit. Transactions of the ASAE, 43(1), 101-109. 
Bajwa, S. G., \& Bories, E. D. (2007). Spatial analysis of cotton (Gossypium hirsutum L.) canopy responses to irrigation in a moderately humid area. Irrigation Science, 25, 429-441.

Boonen, C. (2005). On-line measurement and modelling of dynamic plant responses to variations of the microenvironement. (Doctoral Dissertation).

Boonen, C., Aerts, J. M., \& Berckmans, D. (2002). Mathematical modelling of the fast dynamic response of tomato leaves to sudden changes in microclimate. Acta Horticulturae, 221-228.

Boonen, C., Joniaux, O., Janssens, K., Berckmans, D., Lemeur, R., Kharoubi, A., \& Pien, H. (2000). Modeling dynamic behavior of leaf temperature at three-dimensional positions to step variations in air temperature and light. Transactions of the ASAE, 43(6), 1755-1766.

Campbell Scientific, Inc. (1992). Eppley PSP Precision Spectral Pyranometer Instruction Manual. Logan, Utah, United States of America.

Cengel, Y. A., \& Boles, M. A. (2002). Temperature Sensors and Infrared Temperature Measurements. In Y. A. Cengel, \& M. A. Boles, Thermodynamics: an Engineering Approach (pp. 202-237). Highstown, NJ, NJ: McGraw-Hill, Inc.

Costa Farms. (2018). Prayer Plant. Retrieved from Costa Farms: http://www.costafarms.com/plants/prayer-plant

Decagon Devices, Inc. (2010). EC-20, EC-10, EC-5 Soil Moisture Sensors User's Manual. 10. Pullman, Washington, United States of America.

Dyer, M. H. (2018). Fertilizing Basil Plants: How And When To Feed Basil. Retrieved from Gardening Know How: https://www.gardeningknowhow.com/edible/herbs/basil/fertilizing-basil-plants.htm

FLIR Systems, Inc. (2016). User's Manual FLIR Exx Series. Wilsonville, Oregon, United States of America.

Grant, O. M., Tronina, L., Jones, H. G., \& Chaves, M. M. (2007). Exploring thermal imaging variables for the detection of stress responses in grapevine under different irrigation regimes. Journal of Experimental Botany, 58(4), 815-825.

GrowAce. (2018). S720 Advance Spectrum MAX LED Grow Light Panel. Retrieved from GrowAce.com: http://growace.com/s720-advance-spectrum-max-led-grow-light-panel.html

Guide-to-Houseplants.com. (2018). Golden Pothos or Devil's Ivy. Retrieved from Guide to Houseplants: http://www.guide-to-houseplants.com/pothos.html

Hashimoto, Y., Ino, T., Kramer, P. J., Naylor, A. W., \& Strain, B. R. (1984). Dynamic analysis of water stress of sunflower leaves by means of a thermal image processing system. Plant Physiology, 76, 266-269.

Hashimoto, Y., Morimoto, T., \& Fukuyama, T. (1985). Some speaking plant approach to the synthesis of control system in the greenhouse. Acta Horticulturae, 174, 219-226.

Idso, S. B., Reginato, R. J., Reicosky, D. C., \& Hatfield, J. L. (1981). Determining soil-induced plant water potential depressions in Alfalfa by means of infrared thermometry. Agronomy Journal, 73(5), 826-830.

Jackson, R. D., Idso, S. B., Reginato, R. J., \& Pinter Jr., P. J. (1981). Canopy temperature as a crop water stress indicator. Water Resources Research, 17(4), 1133-1138.

Jones, H. G. (1999). Use of thermography for quantitative studeis of spatial and temporal variation of stomatal conductance over leaf surfaces. Plant, Cell and Environment, 2, 1043-1055.

LabJack. (2018). EI1050 Digital Temperature/Humidity Probe. Retrieved from LabJack Measurement \& Automation: https://labjack.com/accessories/ei1050-digital-temperaturehumidity-probe

LabJack Corporation. (2004, December 22). LabJack U12 User's Guide. Lakewood, Colorado, United States of America.

LI-COR, Inc. (n.d.). LI-190SA Quantum Sensor. Lincoln, Nebraska, United States of America.

MicroDAQ.com LTD. (2017). 8 Channel Thermocouple and Voltage USB Data Acquisition DAQ Module. Retrieved from MicroDAQ.com: https://www.microdaq.com/measurement-computing-usb-tc-ai-daq.php

Mikron Infrared. (n.d.). Industrial Fixed Mount Thermometers. 4-6. Oakland, New Jersey, United States of America. 
National Conrol Devices. (2013). ProXR Enhanced Quick Start Guide. Osceola, Missouri, United States of America.

Nise, Norman S. (1992). Control Systems Engineering. The Benjamin/Cummings Publishing Company, Redwood City, CA, 756 pp.

Omega Engineering, Inc. (1994). IRt/c Series OS36, OS37, OS38 Infrared Thermocouples Operator's Manual. Stamford, Connecticut, United States of America.

Ondimu, S., \& Murase, H. (2008). Water stress detection in Sunagoke moss (Rhacomitrium canescens) using combined thermal infrared and visible light imaging techniques. Biosystems Engineering, 100, 4-13.

Pascoe, M. (2017). Tradescantia spathacea. Retrieved from World Plants: North America's Largest Plant Database: https://worldplants.ca/display0.php?id=4715

Payero, J. O., Neale, C. U., \& Wright, J. L. (2005). Non-water-stressed baselines for calculating crop water stress index (CWSI) for alfalfa and tall fescue grass. Transactions of the ASAE, 48(2), 653-661.

Pitacco, A., \& Gallinaro, N. (1996). Micrometeorological assessment of sensitivity of canopy resistance to vapour pressure deficit in a Mediterranean oak forest. Annales des sciences forestieres, 53, 513-520.

Plant Identification. (2018). Oxalis triangularis. Retrieved from Plant Identification: https://plantsam.com/oxalistriangularis/

Prenger, J. J. (2003). Development of a plant response feedback irrigation control system based on crop water stress index and evapotranspiration modeling. (Doctoral Dissertation).

Prenger, J. J., Ling, P. P., Hansen, R. C., \& Keener, H. M. (2005). Plant response-based irrigation control system in a greenhouse: system evaluation. Transactions of the ASAE, 48(3), 1175-1183.

Schymanski, S. J., Or, D., \& Zwieniecki, M. (2013). Stomatal Control and Leaf. Thermal and Hydraulic Capacitances under Rapid Environmental Fluctuations. PLOS One, 8(1), 1-16.

Stevens, E.E., G.E. Meyer, \& E.T. Paparozzi (2018). Dynamic Classification of Moisture Stress Using Canopy and Leaf Temperature Responses to a Step Changes of Incident Radiation. Unpublished Honors Thesis. (C) Digital Commons@University of Nebraska-Lincoln.

Woebbecke, D. M., Al-Faraj, A., \& Meyer, G. E. (1994). Calibration of large field of view thermal and optical sensors for plant and soil. Transactions of the ASAE, 37(2), 669-677. 